\title{
MARCAS \\ DE USO EM \\ DICIONÁRIOS \\ ESCOLARES \\ TIPO 2
}

\section{MARCAS DE USO EN DICCIONARIOS ESCOLARES TIPO 2}

\section{LABELS IN TYPE 2 SCHOOL DICTIONARIES}

Fábio Henrique de Carvalho Bertonha*

Universidade Estadual Paulista - São José do Rio Preto

RESUMO: Neste artigo, pretendemos refletir sobre dicionários escolares que estão inseridos no PNLD 2012: Dicionário, que se divide em quatro grupos de dicionários voltados ao Ensino Fundamental; desse agrupamento, interessa-nos examinar aqueles do Tipo 2 por serem as primeiras obras dicionarísticas nas quais aparecem marcas de uso (nosso objeto de pesquisa). Dentre os sete dicionários pertencentes a esse grupo, analisamos Geiger (2011) e Saraiva Júnior (2009), comparando suas etiquetas àquelas de Houaiss (2009) e Ferreira (2010). Baseando-nos em Fajardo (1997), Strehler (1998), Garriga Escribano (2003), Welker (2004), Zavaglia (2009) e Gutiérrez Cuadrado (2011), notamos que as marcas são usadas para destacar, além de contextualizar, itens próprios ao universo infantil. Resulta que não há uma padronização metodológica quanto à escolha de um rótulo em detrimento a outro, tampouco pedagógica, propósito primeiro ao consulente escolar, para sua produção textual.

PALAVRAS-CHAVE: Metalexicografia. Dicionário Tipo 2. Marcas de uso.

RESUMEN: En este artículo, pretendemos reflexionar sobre los diccionarios escolares integrados en el PNLD 2012. Diccionario, que se divide en cuatro grupos de diccionarios destinados a la Enseñanza Básica; de esa agrupación, nos interesa examinar los de Tipo 2 , porque son las primeras obras diccionarísticas en las que aparecen marcas de uso (nuestro objeto de investigación). Entre los siete diccionarios pertenecientes a este grupo, analizamos Geiger (2011) y Saraiva Júnior (2009), comparando sus etiquetas con las de Houaiss (2009) y Ferreira (2010). Basándonos en Fajardo (1997), Strehler (1998), Garriga Escribano (2003), Welker (2004), Zavaglia (2009) y Gutiérrez Cuadrado (2011), observamos que se utilizan las marcas para resaltar, además de contextualizar, elementos propios del universo infantil. Se deduce que no hay una estandarización metodológica con respecto a la elección de una etiqueta sobre otra, ni una pedagógica, propósito inicial para el estudiante que consulta y para su producción textual.

PALABRAS CLAVE: Metalexicografia. Diccionario Tipo 2. Marcas de uso.

ABSTRACT: In this paper, we intend to reflect on school dictionaries inserted in the PNLD 2012: Dicionário, which divides into four groups of dictionaries aimed at Elementary School; from this group, we are interested in checking those of Type 2 because they are the

\footnotetext{
* Doutorando no Programa de Pós-Graduação em Estudos Linguísticos na UNESP-IBILCE (bolsista CAPES), cuja linha de pesquisa é Lexicologia e Lexicografia, tradutor autonomo e professor das línguas de formação (português, inglês, italiano,francêseespanhol).E-mail: bertonha.tradutor@hotmail.com.
} 
first dicionaristic works in which labels appear (our research object). Among seven dictionaries belonging to this group, we analysed Geiger (2011) and Saraiva Júnior (2009), comparing their labels to those of Houaiss (2009) and Ferreira (2010). Based on Fajardo (1997), Strehler (1998), Garriga Escribano (2003), Welker (2004), Zavaglia (2009), and Gutiérrez Cuadrado (2011), we note that labels are used to highlight, in addition to contextualizing, items suitable for the childish universe. It results there is neither methodological standardization regarding the choice of one label over another, nor pedagogical, purpose first to educational consultant, for his/her textual production.

KEYWORDS: Metalexicography. Type 2 dictionary. Labels.

\section{INTRODUÇÃO}

O tema central do presente artigo refere-se a uma reflexão sobre dicionários escolares infantis a partir da tipologia estabelecida pelo Programa Nacional do Livro Didático (PNLD), o qual tem como uma de suas ramificações a publicação intitulada "PNLD 2012: Dicionário", que estabelece a divisão de quatro tipos de dicionários, sendo que três (Tipo 1, Tipo 2 e Tipo 3 ) são voltados para o Ensino Fundamental (EF) e um (Tipo 4) direcionado ao Ensino Médio (EM). Em particular, algumas marcas de uso encontradas nos verbetes em dois dos dicionários do grupo Tipo 2 serão comparadas a outras duas obras dicionarísticas legitimadas pelo público brasileiro: Houaiss (2009) e Ferreira (2010).

Inicialmente, é importante destacar que esse programa supracitado surge a partir de políticas públicas - deliberações tomadas pelo Estado a fim de sanar problemas de ordem social por meio de ações governamentais direcionadas a áreas específicas (educação, segurança, ambiente, saúde, entre outras). Com relação à área educacional, evidenciam-se o Plano Nacional da Educação (PNE), o Fundo Nacional de Desenvolvimento da Educação Básica e de Valorização do Magistério (FUNDEB) e o Sistema de Avaliação da Educação Básica (SAEB), sendo que, em meio às ações e aos programas propostos integrados ao PNE, distingue-se o Programa Nacional do Livro Didático (PNLD), criado ainda na década de 1980 (precisamente, 1985), tendo o intuito de avaliar, selecionar e distribuir livros didáticos que possam atender às necessidades e aos princípios educacionais norteadores das escolas públicas do Brasil.

A cada trienal alternado, esse programa abarca três segmentos da Educação Básica de maneira tal que o governo consegue avaliar, selecionar e distribuir livros didáticos aos anos iniciais ou finais do Ensino Fundamental (EF), ou mesmo para o Ensino Médio (EM), portanto, procura atender às necessidades via ferramentas que auxiliem o educador no ambiente de aula, ou seja, com livros didáticos - diretamente ligados ao processo de ensino-aprendizagem.

Quinze anos mais tarde, em 2000, o PNLD inseriu, em seu rol de obras didáticas, os dicionários, que passaram a ser avaliados, selecionados e distribuídos, fato esse que desencadeou um avanço na formulação de obras dicionarísticas direcionadas ao público escolar, visto que grandes editoras brasileiras deram início a investimentos para desenvolvê-las para serem usadas em ambientes educacionais.

Entretanto, é nítida a ausência de (in)formação por parte dos docentes em utilizar, de modo eficaz, o dicionário, tanto por ser uma prática educacional adotada muito recentemente quanto por não haver um aprofundamento reflexivo durante a formação dos educadores sobre como aproveitar a potencialidade das obras lexicográficas. O governo procura, por meio do edital do "PNLD 2012: Dicionário", vencer esse obstáculo ao estipular critérios particulares a serem preenchidos para a seleção dessas obras, cujos parâmetros exigidos são atendidos pelas editoras, beneficiando a produção lexicográfica que visa atender às necessidades de seus consulentes.

\section{OBJETIVOS DA PESQUISA}

Desejamos investigar o registro das marcas de uso em dicionários do Tipo 2, procurando analisar de que forma estão inseridas na descrição dos itens lexicais que recebem esse tipo de informação. Especificamente, objetivamos refletir e avaliar o modo como esses 
dicionários indicam seus usos mediante os rótulos estabelecidos, bem como o questionamento da presença ou da ausência deles e, ainda, qual a relação estabelecida com outros elementos do verbete, se é que existe um vínculo, e, em existindo, onde está. Logo, indagamo-nos se, de fato, essas obras lexicográficas fazem essa marcação, se as descrições rotuladas apresentam um padrão e de que modo as fazem. Para tanto, neste momento, debruçamo-nos sobre Geiger (2011) e Saraiva Júnior (2009), em circulação no país, e suas marcas de uso, comparando-as àquelas presentes em Houaiss (2009) e Ferreira (2010).

\section{DELIMITAÇÃO DO CORPUS}

Dentre as obras selecionadas pelo "PNLD 2012: Dicionário", houve uma divisão em quatro tipos, sendo que, para este artigo, servemnos duas daquelas enquadradas no Tipo 2 (correspondentes ao período educacional entre o segundo e o quinto ano do EF), pois são as primeiras evidenciadas com a presença de marcas de uso, perfazendo um total de sete obras, a saber: (i) Biderman, Maria Tereza Camargo. Dicionário ilustrado de português. 2 ed. São Paulo: Ática, 2009. [5.900 verbetes]; (ii) Borba, Francisco S. Palavrinha viva; dicionário ilustrado da língua portuguesa. Curitiba: Piá, 2011. [7.456 verbetes]; (iii) Braga, Rita de Cássia Espechit; Magalhães, Márcia A. Fernandes. Fala Brasil!; dicionário ilustrado da língua portuguesa. Belo Horizonte: Dimensão, 2011. [5.400 verbetes]; (iv) Ferreira, Aurélio Buarque de Holanda. Dicionário Aurélio ilustrado. Curitiba: Positivo, 2008. [10.243 verbetes]; (v) Geiger, Paulo (org.). Caldas Aulete - Dicionário escolar da língua portuguesa; ilustrado com a turma do Sítio do Pica-Pau Amarelo. 3 ed. São Paulo: Globo, 2011. [6.183 verbetes]; (vi) Mattos, Geraldo. Dicionário júnior da língua portuguesa. 4 ed. São Paulo: FTD, 2011. [14.790 verbetes]; e (vii) Saraiva, Kandy S. de Almeida; Oliveira, Rogério Carlos G. de. Saraiva Júnior; dicionário da língua portuguesa ilustrado. 3 ed. São Paulo: Saraiva, 2009. [7.040 verbetes]. Essas sete obras possuem em comum o fato de terem um mínimo de três mil e um máximo de quinze mil verbetes, além de uma proposta lexicográfica adequada a estudantes que se encontram em fase de consolidação do domínio tanto da escrita quanto da organização e da linguagem típicas do gênero dicionário. Nosso recorte se dá por duas dessas obras: Geiger (2011) e Saraiva Júnior (2009).

\section{FUNDAMENTAÇÃO TEÓRICA}

Ao se buscar um significado no dicionário, é necessário que se faça uma reflexão, uma interpretação no conjunto (con)textual, tendo em vista as várias dimensões de conhecimento que compõem esse conteúdo informacional. É preciso mencionar o papel daquele que produz a obra, pois, independentemente de qual seja o dicionário, a 'presença' do lexicógrafo, enquanto sujeito social, inevitavelmente trará ideias e concepções concernentes à sociedade de que faz parte (ORLANDI, 2000). O árduo trabalho de rotulação enfrentado por lexicógrafos é constatado por Welker (2004). De fato, como apresentam um caráter de certo modo intuitivo e pouco compreendido pelos consulentes, as marcas de uso, por vezes, são arbitrárias. Logo, apoiamo-nos em trabalhos e pesquisas metalexicográficas de Fajardo (1997), Strehler (1998), Garriga Escribano (2003), Welker (2004), Zavaglia (2009) e Gutiérrez Cuadrado (2011) a fim de obtermos êxito em nossas análises.

\subsection{CONCEITUAÇÃO DE 'LÉXICO’}

Segundo Vilela (1979), 'léxico' é a representação de um sistema de possibilidades que abarcam todas as palavras documentadas e aquelas possíveis de serem constituídas a partir de suas bases de formação. Já para Biderman (1981), era tido como 'tesouro vocabular' de uma língua, tendo sua nomenclatura composta por conceitos linguísticos e não linguísticos usados pelo homem contemporâneo e do passado. Quase ao final do século, Biderman (1996, p. 27) resgata seu conceito de 'léxico’ e estabelece que “[...] é o lugar de estocagem da significação e dos conteúdos significantes da linguagem humana”.

Em meados do século XXI, Borba (2003 apud MARCHEZAN; CORTINA, 2006, p. 81) afirma que 'léxico’ é aquilo que faz a conexão entre a abstração da língua e a realidade em si, de modo que "o léxico fisionomiza a cultura". "O léxico é, pois, o conjunto de todos os itens lexicais existentes em uma língua natural, incluso aí expressões, fraseologismos, itens gramaticais. É um conjunto aberto, em contínua expansão, impossível de ser delimitado em sua totalidade” (ZAVAGLIA, 2009, p. 7); com isso, podemos sistematizálo em dicionários de língua, organizando-o pela língua geral ou por eixos temáticos. 
Essa mesma organização pode ser realizada eficazmente via Lexicografia que, sem entrar em pormenores, é uma técnica - e por que não dizer uma arte - de se fazer um repertório do léxico, registrando-o em um dicionário. Contudo, o ingênuo inventário de uma listagem de palavras não garante valor expressivo, pois somente se encontra o verdadeiro valor quando, na compilação, fica evidenciada a reflexão científica sobre a maneira de descrever e de classificar para, na sequência, ser dado início à formulação dos verbetes (ZAVAGLIA, 2009).

\subsection{DICIONÁRIO: UM PRODUTO LEXICOGRÁFICO}

Obra de consulta a qual representa uma descrição do léxico, o dicionário se constitui por meio de quatro variáveis: (i) número e extensão das entradas; (ii) modo de estudá-las; (iii) ordenação apresentada; e (iv) suporte da descrição. Portanto, conforme Porto Dapena (2002), não há tipos uniformes de dicionários, quer dizer, todo dicionário pode pertencer, ao mesmo tempo, a várias classificações.

Constata-se a existência de uma ampla oferta de "dicionários" no mercado, por razões variadas: para atender às necessidades específicas de certos públicos; para catalogar, parcialmente, o léxico de um povo (provérbios, terminologia de negócios etc.), para incentivar novas pesquisas em áreas específicas do conhecimento (astrofísica), uni, bi ou plurilíngues, impressos, eletrônicos ou online etc. Entretanto, por vezes, essas obras chamadas e vendidas como "dicionários", de fato, não são obras pensadas para constituir um dicionário (HARTMANN, 1985 apud BÉJOINT, 2000).

Por fim, é preciso que se mencione o papel do elaborador desse tipo de gênero textual, visto que, seja qual tipo for, o lexicógrafo é um sujeito do seu tempo, um sujeito social e, inevitavelmente, leva suas concepções referentes à sua sociedade para a constituição do dicionário (ORLANDI, 2000). Apesar do desejo por uma postura isenta para atingir seus consulentes de forma 'imparcial', verificamos que, naquilo que concerne à Lexicografia, 'a neutralidade é somente aparente', a qual pode ser evidenciada pela presença das marcas de uso, cuja valorização social, ou não, dissemina uma intencionalidade flagrante pela expressão escrita da definição (GUTIÉRREZ CUADRADO, 2011)

\subsubsection{Dicionários Voltados ao Público Escolar Infantil}

Dentre as tipologias lexicográficas, segundo a proposta do Programa Nacional do Livro Didático (PNLD) dividida em quatro categorias, tendo em vista usuário, escolaridade e volume de informação contida nos dicionários, interessa-nos aqueles do Tipo 2. Essa categorização advém do "PNLD 2012: Dicionário", conforme o Quadro 1. 


\begin{tabular}{|c|c|c|}
\hline $\begin{array}{l}\text { Tipo de } \\
\text { dicionário }\end{array}$ & $\begin{array}{l}\text { Fase educacional em que o } \\
\text { estudante se encontra }\end{array}$ & Características \\
\hline Tipo 1 & $1^{\circ}$ ano do EF & $\begin{array}{l}\text { Proposta lexicográfica apropriada às demandas do processo de alfabetização inicial; de } 500 \\
\text { a } 1.000 \text { verbetes. }\end{array}$ \\
\hline Tipo 2 & $\begin{array}{l}\text { Período entre o } 2^{\circ} \text { e o } 5^{\circ} \text { ano } \\
\text { do EF }\end{array}$ & $\begin{array}{l}\text { Proposta lexicográfica apropriada a estudantes em fase de consolidação do domínio tanto } \\
\text { da escrita quanto da organização e da linguagem típicas do gênero dicionário; de } 3.000 \text { a } \\
15.000 \text { verbetes. }\end{array}$ \\
\hline Tipo 3 & $\begin{array}{l}\text { Segundo segmento do } \mathrm{EF}\left(6^{\circ}\right. \\
\left.\text { ao } 9^{\circ} \text { ano }\right)\end{array}$ & $\begin{array}{l}\text { Proposta lexicográfica direcionada pela caracterização de um dicionário padrão de uso } \\
\text { escolar, porém, apropriada aos estudantes que se encontram nos últimos anos do Ensino } \\
\text { Fundamental; de } 19.000 \text { a } 35.000 \text { verbetes. }\end{array}$ \\
\hline Tipo 4 & $1^{\circ}$ ao $3^{\circ}$ ano do EM & $\begin{array}{l}\text { Proposta lexicográfica própria de um dicionário padrão, porém, apropriada às demandas } \\
\text { escolares do Ensino Médio, inclusive o profissionalizante; de } 40.000 \text { a } 100.000 \text { verbetes. }\end{array}$ \\
\hline
\end{tabular}

Quadro 1: Tipologias estabelecidas pelo "PNLD 2012: Dicionário”

Fonte: Brasil (2012)

Considerando-se que a Metalexicografia escolar infantil examina dicionários escolares ao público infantil (público-alvo) e seus objetivos particulares, nota-se que há críticas que podem ser levantadas às obras já existentes, com o intuito de motivar uma reflexão linguístico-metodológica a respeito do próprio objeto de estudo: dicionário escolar infantil. Neste artigo, o foco corresponde àqueles do Tipo 2, nos quais, primeiramente, são utilizadas as marcas de uso, pois aqueles classificados como pertencentes ao grupo do Tipo 1 não as utilizam.

De acordo com Krieger (2006, p. 247), o conjunto de fatores que envolvem o dicionário no contexto escolar passou a ser entendido como Lexicografia Didática, cujas obras se voltam para atender todos os níveis educacionais e, assim,

[...] como uma produção direcionada à escola é de extrema importância sobretudo porque há uma tendência geral de identificar como escolar os dicionários tipo mini. No entanto, a compreensão do caráter escolar costuma estar associada mais às suas dimensões reduzidas do que à sua efetiva adequação ao ensino/aprendizagem da língua. Por isto, apesar de práticas, as versões sintéticas nem sempre são as melhores para uso escolar.

Verifica-se que a Lexicografia voltada para atender ao público infantil visa repertoriar as unidades lexicais peculiares e predominantes no âmbito dos consulentes infantis, isto é, almeja compilar obras dicionarísticas orientadas ao universo infantil que, da mesma maneira, merecem um juízo crítico avaliativo expresso pelos lexicógrafos com relação à Lexicografia Infantil.

Retomando Haensch (1982, p. 127), tem-se que um dicionário escolar é caracterizado como sendo "uma obra de consulta que não deve afligir um aluno com excesso de informações e que, além disso, tem de ser econômico", quer dizer, deve primar por uma extensão reduzida; além disso, ainda afirma que, "[...] geralmente, os dicionários escolares (monolíngues ou bilíngues) que são usados nos colégios e/ou nas universidades são insuficientes tanto no que diz respeito à extensão quanto ao recrutamento das entradas". Com isso, constata-se que a terminologia utilizada à tipologia de dicionários infantis não possui uma estabilidade referente ao termo empregado, pois, concomitantemente ao uso de "dicionário escolar", aparenta corresponder a toda e qualquer obra que se refira aos universos escolar e infantil.

Ainda para a caracterização dos dicionários infantis, Welker (2008, p. 295) afirma que "fazem parte dos dicionários pedagógicos de língua materna (DPLMs) não somente os dicionários escolares como também, por um lado, os dicionários infantis (DIs)". Sob outra perspectiva, tanto Climent de Benito (2005) quanto Corbin (2001) explicitam que esses tipos de dicionários, de fato, nessa ordem, 
correspondem a um Dicionário de Iniciação e a um Pré-dicionário (apud WELKER, 2008). Já Biderman (1984) denomina Dicionário Escolar como Dicionário Infantil.

Notadamente, vê-se que não há limites claros entre dicionários escolares e infantis, por isso não se pode, imediatamente, reconhecer conteúdo nem público-alvo, haja vista a não ocorrência de uma terminologia coincidente, podendo ser encontrados Dicionário Escolar, Dicionário Infantil, Dicionário Escolar Infantil, Dicionário de Iniciação, Pré-dicionários.

Para o escopo deste artigo, baseamo-nos na concepção de dicionário escolar utilizada pelo "PNLD 2012: Dicionário", que corresponde a obras cuja proposta lexicográfica

[...] não só se mostra compatível com essas atividades como é pensada para propiciar o seu desenvolvimento; e, entre eles [os dicionários], são ainda mais adequados os que foram concebidos e elaborados para atender a essas demandas específicas. Como uma dessas demandas [de ensino e aprendizagem] é exatamente a da adaptação do que se quer ensinar/aprender ao nível de ensino e aprendizagem visado, podemos acreditar que os dicionários orientados para faixas específicas serão mais eficazes em seus propósitos pedagógicos. Na medida em que os dicionários escolares disponíveis no mercado livreiro visam diferentes públicos, obedecem a diferentes propostas e são realizados com graus variados de rigor, podem se revelar mais ou menos adequados para a consecução dos objetivos pedagógicos visados. (BRASIL, 2012, p. 18)

Para nossas discussões, trataremos dos dicionários escolares do Tipo 2, conforme categorização anteriormente mencionada, tomando-se como referência três aspectos, os quais temos (i) projetos aos quais os dicionários estejam relacionados, (ii) parâmetros descritivos lexicográficos precisos e, por fim, (iii) metas da educação básica em cada um de seus níveis de ensino.

\subsection{OBJETO DE ESTUDO: AS MARCAS DE USO}

A fim de favorecer a descrição das unidades lexicográficas, as marcas de uso (também chamadas na literatura de 'etiquetas', 'rubricas', 'rótulos') se apresentam como componentes substanciais na constituição dos verbetes dos dicionários. Lara (2004) evidencia a importância da 'etiquetagem’ na definição, para que a obra lexicográfica seja capaz de colaborar para a compreensão do item lexical nos diversos contextos. Observa-se que elas são os recursos constantemente utilizados ao se tratar da variação linguística, apontando para o fato de que "[...] as marcas de uso caracterizam as palavras que fogem, sob certos aspectos, ao uso corriqueiro, normal, da língua de uma comunidade linguística” (STREHLER, 1998, p. 172).

Garriga Escribano (2003) afirma que as marcas são utilizadas para assinalar que os itens lexicais apresentam restrições de uso, entretanto, são fundamentais para os consulentes, mesmo que sua disposição nos dicionários, em geral, ocorra de forma assistemática e pouco objetiva. Porto Dapena (2002, p. 249), em contrapartida, acredita que o consulente dê pouca atenção a elas por desconhecer o significado das abreviaturas, sendo que a isso há ainda imprecisão e incoerência na maneira como são apresentadas, corroborando para o desinteresse em compreendê-las.

No verbete, esperam-se informações que façam referência: (i) ao registro ('formal', 'informal', 'coloquial', 'literário' ou 'gíria') em que determinada palavra ou sentido seja utilizado; (ii) à hodiernidade ('arcaico' ou 'em desuso'); (iii) à limitação geográfica (espaço por onde a palavra ou sentido é utilizado); (iv) ou ainda ao efeito de sentido que tal uso possa causar ('jocosidade', 'eufemismo' ou 'pejoratividade').

Conforme aponta Lara (1996), historicamente, esses 'rótulos’ são normativos, uma vez que advertem o usuário do dicionário quanto ao uso; no entanto, esse mesmo autor reconhece que, na atualidade, as marcas têm se tornado mais descritivas que normativas, almejando localizar social, morfológica ou genealogicamente as palavras e os usos registrados.

Também a questão da assistematicidade é apontada por Borba (2003, p. 315), referindo-se à inclusão das marcas, visto que “[...] os dicionários costumam incluir este tipo de informação por um conjunto de rótulos, tarefa complicada e feita de forma irregular em nossos dicionários”. Com frequência, a relação estabelecida entre as marcas e outros componentes do verbete podem gerar 
ambiguidades na medida em que a marca poderia se referir a uma única ou a várias acepções; por isso, Welker (2004, p. 134) destaca a relevância das marcas de uso na constituição do verbete e posterior consulta: "[...] apesar de todas as dificuldades, seria desejável que houvesse mais marcas de uso do que se verificam na maioria dos dicionários. Elas são imprescindíveis quando se precisa de ajuda na produção de textos, mas também são importantes na recepção, pois sem elas não se alcança uma compreensão exata do texto.".

Graças a elas, é possível indicar ao consulente quais as restrições de uso de determinada unidade lexicográfica, atualizando-a quanto ao seu status no sistema linguístico. Para tanto, Garriga Escribano (2003) subdivide as marcas em diacrônicas, diatópicas, diafásicas, diastráticas, diatécnicas e marcas de transição semântica.

Em meio à Lexicografia espanhola, Fajardo (1997) assinala os muitos problemas que envolvem o uso das etiquetas nas obras lexicográficas. Eles vão desde a ausência de uma definição transparente quanto aos valores atribuídos a cada um dos rótulos usados nos dicionários até a sobreposição de dois ou mais valores sem que, explicitamente, seja marcada a diferença entre eles, tais como 'popular' e 'coloquial' ou 'antiquado', 'arcaico', 'desuso' e 'obsoleto'. Esse mesmo autor ainda discorre sobre a importância de uma sistematização das marcas de uso, buscando eliminar possíveis ambiguidades ou mesmo repetições desnecessárias.

No caso da etiqueta 'figurado', Garriga Escribano (2003) a classifica como uma marca de transição semântica, demonstrando que esse tipo de etiqueta representa um problema em relação ao tipo de informação que abrange. Um sentido figurado se fundamenta a partir de um sentido denotativo que origina outros, por um processo metafórico. Ainda esse mesmo autor indica que, nos dicionários da língua espanhola, a etiqueta 'figurado' tem apresentado um alto uso, entretanto, destaca que é difícil precisar quando uma acepção tem origem a partir de outra (dificuldades em atestar a etimologia), se há um desconhecimento quanto ao fato de qual das duas teria surgido primeiro. Inclusive, a dificuldade de se precisar o critério utilizado nos dicionários na aplicação da etiqueta 'figurado’ se evidencia em Casares (1992 apud GARRIGA ESCRIBANO, 2003, p. 119) quando afirma "[...] que a abreviatura fig. esbanja-se muito nos dicionários, mas de maneira pouco cuidadosa”.

Logo, percebemos que falta aporte teórico no qual a Lexicografia possa se sustentar para o estabelecimento de uma classificação unânime quanto às marcas de uso, resultando em abordagens superficiais, subjetivas e discordantes nos dicionários. Assim, visto que há distinção controversa, torna-se pertinente o exame dessas marcações e a problematização da ausência de etiquetas, sobretudo pelo fato de que, em dicionários eletrônicos, esses elementos constituintes da microestrutura podem ser utilizados como chaves de busca, dos quais pode ser manifestada uma ideologia.

\section{METODOLOGIA EMPREGADA DURANTE A INVESTIGAÇÃO}

Para este artigo, levantamos e efetivamos o corpus de investigação, que corresponde aos verbetes em Geiger (2011) que contenham marcas de uso. Em um segundo momento, coletamos as marcas de uso contidas nos verbetes desse nosso corpus. A partir dessa recolha, via coleta manual, foram encontradas e analisadas 41 rubricas presentes nos 1124 verbetes do dicionário Caldas Aulete (GEIGER, 2011), cuja extensão da nomenclatura equivale a um total de 6.183 verbetes. Por fim, comparamos uma amostra dela àquelas encontradas em outra obra do grupo Tipo 2 - Saraiva Júnior (2009) - e àquelas em Houaiss (2009) e em Ferreira (2010), sendo assim, pretendemos analisar as seguintes unidades lexicográficas: 'abacaxi', 'abafado', 'badalar', 'bafo', 'parasita', 'galera', 'galho', 'pintar', 'pinto', 'pipa' e 'traçar'.

A escolha por esse grupo de dicionários foi motivada pela possibilidade de análise intralinguística, observando semelhanças e diferenças na língua portuguesa, variante brasileira, pois desejamos observar como as marcas de uso apresentadas são construídas na conjuntura social brasileira, sobretudo em meio ao universo escolar infantil. Analisamos os dicionários pela observação dos enunciados presentes nos verbetes e, na sequência, propomos algumas considerações comparativas. 


\section{DISCUSSÃO E ANÁLISE}

Entendemos que as marcas se fazem presentes para destacar itens próprios e singulares ao universo infantil e são tidas como necessárias por seus respectivos lexicógrafos. Em Geiger (2011), as rubricas utilizadas em 1124 unidades lexicográficas pertencentes à nomenclatura do dicionário atestam ausência de sistematização metodológica, com relação a uma escolha em detrimento a outra, e também pedagógica, finalidade primeira para o consulente escolar, na produção de seus textos. Por exemplo, a unidade lexicográfica 'bafo' (que será tratada mais detidamente adiante) apresenta duas etiquetas ('gíria' e 'popular'), as quais auxiliariam o consulente em sua busca? O que difere 'gíria' de 'popular'? E quanto à lexia 'vida', que apresenta três rubricas ('figurado', 'familiar' e 'popular'), poderíamos esperar que o consulente que se encontra no período educacional entre o segundo e o quinto ano (entre sete e onze anos de idade) do EF fosse capaz de diferenciá-las? São questões como essas que motivam nossas análises.

Essas etiquetas presentes em Geiger (2011) se apresentam não abreviadas, em negrito azul, logo após a numeração da acepção, um destaque favorável para a percepção por parte dos consulentes. Aproveitamos para comparar algumas entradas desse dicionário escolar a outros dois dicionários considerados como padrões de legitimação na sociedade brasileira, sendo um deles Houaiss (2009) doravante HO - e o outro Aurélio (FERREIRA, 2010) - doravante AU -, a fim de refletirmos a respeito da etiquetagem visando ao público infantil.

Ainda em Geiger (2011), a indicação de uso em diferentes situações ou em contextos específicos é fundamental para entender as unidades lexicográficas representadas e divididas em três grupos: a) regionalismos, quando se referem a lexias referentes a um estado ou região específicos (tal como, 'bombachas' com a marca 'Sul'); b) nível de linguagem como gíria, popular, depreciativo etc. (por exemplo, "camelo. gíria. É o mesmo que bicicleta."); c) área do conhecimento, quando a lexia corresponde a uma específica área, como "subtração. matemática”.

No Saraiva Júnior, as marcas de uso aparecem abreviadas, em itálico, após a numeração das acepções, indicando os diferentes níveis de formalidade/expressividade, sendo que aquelas utilizadas para referenciar as lexias servem para indicar lexias com linguagem gírica, popular, familiar, figurada ou mesmo chula, assim como aquelas que marcam determinadas regiões do Brasil estão contempladas pelas marcas diatópicas dos estados brasileiros (SC, RS etc.) que também serão comparadas àquelas de $\mathrm{HO}$ e de AU.

Vejamos alguns exemplos de unidades lexicográficas dessas quatro obras dicionarísticas. Iniciemos por 'abacaxi’.

\begin{tabular}{c|c} 
Quantidade de acepções em Geiger (2011) & Rubrica(s) \\
\hline 2 & gíria \\
Quadro 2: Entrada abacaxi’ & \\
Fonte: Elaborado pelo autor &
\end{tabular}

Na entrada 'abacaxi', em sua segunda acepção, a rubrica gíria destaca e explica ao consulente estudantil que "como o abacaxi dá trabalho para descascar, também dizemos que uma situação difícil ou incômoda é um abacaxi”. Comparando-se essa mesma entrada a HO, encontramos tanto em suas oito acepções (com oito rubricas) quanto em sua locução 'descascar um abacaxi' a presença de marcas de uso, dentre as quais verifica-se também o sentido de algo difícil para ser resolvido; entretanto, no verbete infantil, não consta essa locução (marcada como 'Regionalismo: Brasil. Uso: informal') de HO. Já em AU, 'abacaxi' contém seis acepções (das quais cinco têm rubricas) e uma locução (também com rubrica), e, assim como em Houaiss, também apresentam o sentido do dicionário escolar, no qual não consta a locução “Descascar um abacaxi”, marcada por 'pop' em AU. Na sequência, temos 'abafado'.

\begin{tabular}{c|c} 
Quantidade de acepções em Geiger (2011) & Rubrica(s) \\
\hline 3 & figurado
\end{tabular}


Quadro 3: Entrada 'abafado'

Fonte: Elaborado pelo autor

A entrada 'abafado’ possui como sua terceira acepção (“dizemos que alguém está abafado quando está muito ocupado, sem tempo para mais nada”) a etiqueta figurado, além de uma subentrada, 'abafar', que tem duas acepções, sendo que a segunda (“ter sucesso”) está marcada como gíria. Da mesma maneira como em 'abacaxi', também em 'abafado’ verificamos um 'nós’ oculto nas definições, porém, poderíamos questionar por que o lexicógrafo fez essas escolhas para o dicionário escolar, baseou-se em quê? Não sabemos, visto que é uma informação omitida do consulente.

No HO, 'abafado' apresenta quatorze acepções, das quais três estão com marcas de registro ('informal') e duas com marcas diatópicas ('Regionalismo: Brasil' e 'Regionalismo: Pernambuco'); essa etiquetagem, se estivesse presente em Geiger (2011), poderia confundir a compreensão das crianças; já 'abafar' possui dezessete acepções, dentre as quais seis rubricas, sendo uma delas aquela que se refere à mesma no dicionário escolar, possui a rubrica 'Regionalismo: Brasil. Uso: informal' ("mostrar-se superior; estar ou ficar em situação de destaque; ser um sucesso").

Por outro lado, em AU, entre as vinte acepções de 'abafar', cinco apresentam rubricas, sendo que uma delas compartilha da rubrica 'Bras. Gír.' presente no dicionário escolar; enquanto que 'abafado' possui três rubricas em meio às suas doze acepções, porém, a que coincide com aquela do dicionário escolar é 'Bras. Pop.' ("Extremamente ocupado; abarbado”), diferentemente de Geiger (2011).

Nossa próxima entrada é ‘badalar’, vejamos:

\begin{tabular}{c|c} 
Quantidade de acepções em Geiger (2011) & Rubrica(s) \\
\hline 3 & popular \\
Quadro 4: Entrada badalar’ & \\
Fonte: Elaborado pelo autor &
\end{tabular}

A unidade lexicográfica 'badalar' é uma entrada com três acepções (GEISER, 2011), cuja terceira apresenta a rubrica popular ("ir a festas, espetáculos, exposições etc.") e, ainda no verbete, consta 'badalação’ também com a marca popular ("ação de estar presente em festas e outros eventos sociais”), uma linguagem acessível a seu público-alvo. Em HO, 'badalar' tem seis acepções, das quais quatro são etiquetadas e, dessas, três estão marcadas por 'Regionalismo: Brasil. Uso: informal', das quais uma dispõe do mesmo sentido marcado no dicionário escolar (“frequentar lugares diversos; passear, divertir-se”); já em 'badalação', das cinco acepções, duas são rotuladas e também há coincidência de sentido encontrado no dicionário escolar 'Regionalismo: Brasil. Uso: informal' ("vida social ativa; divertimento"). Assim, enquanto na obra infantil o lexicógrafo etiquetou com 'popular', em HO, seu grupo de lexicógrafos preferiu usar 'informal', assim, mais uma vez é constatada a não padronização lexicográfica.

Contrariamente a HO, mas da mesma maneira que Geiger (2011), em AU, etiqueta-se com 'pop.' e, das dez acepções, cinco têm rubricas, sendo que sua quarta é "Bras. Pop. Comparecer a reuniões sociais, a festas, etc., de maneira mais ou menos ostentatória; exibir-se; mostrar-se; badalar-se.”; já ‘badalação’ apresenta uma única acepção, que se refere a três da entrada 'badalar', como se verifica em “1. Bras. Pop. Ação ou efeito de badalar (4, 7 a 9).”, ressaltando que essas três referenciadas são rotuladas.

Para a próxima análise, tomemos 'bafo':

\begin{tabular}{c|c} 
Quantidade de acepções em Geiger (2011) & Rubrica(s) \\
\hline 4 & gíria, popular \\
Quadro 5: Entrada bafo' & \\
Fonte: Elaborado pelo autor &
\end{tabular}


Nesse dicionário escolar, 'bafo' compreende quatro acepções, duas têm marcas, gíria ("também é o hálito com cheiro ruim”) e popular ("bafo é também mentir"), e diante delas poderíamos questionar até que ponto essa obra considera uma lexia como gíria e/ou popular. É uma decisão do lexicógrafo? Se sim, baseia-se em quais parâmetros? Seria interessante que os consulentes não fossem privados desse tipo de informação. No HO, há sete acepções, das quais três estão marcadas, e ainda são encontradas duas locuções rotuladas por 'Regionalismo: Brasil. Uso: informal', das quais uma delas remete ao mau hálito ("bafo de onça ou de tigre"), e a outra a mentiras ("bafo de boca") (esse sentido último só aparece contemplado na locução, diferentemente do dicionário escolar, no qual se constata já pela entrada e não pela expressão); embora tenham o mesmo sentido, essa locução não consta em Geiger (2011). Em AU, há cinco acepções e três locuções para a entrada 'bafo', das quais três são etiquetas por 'Bras. Gír.' e uma por 'Fig.'; destaca-se que a menção a mentira não está literalmente expressa em AU, sendo possível encontrá-la em "conversa fiada”, a qual o consulente precisa inferir que se trata de mentira.

Na sequência, temos 'parasita’:

\begin{tabular}{c|c} 
Quantidade de acepções em Geiger (2011) & Rubrica(s) \\
\hline 2 & ciências, depreciativo \\
Quadro 6: Entrada 'parasita' & \\
Fonte: Elaborado pelo autor &
\end{tabular}

Nesse dicionário escolar, a entrada 'parasita’ possui duas acepções, ambas etiquetadas por: a) ciências ("todo organismo que vive dentro de outro à custa dele é um parasita"); b) depreciativo ("diz-se também que é um parasita quem vive à custa dos outros para tirar vantagem deles ou porque é preguiçoso"). Para esse segundo sentido, há também uma advertência, destacada em azul, de que pode ser feito um uso não apenas depreciativo, mas também ofensivo dessa lexia. Em HO, há quatro acepções para a unidade lexicográfica 'parasita' e todas apresentam rubricas, porém, os sentidos coincidentes com aqueles do dicionário escolar, respectivamente, são marcados como 'biologia' e 'pejorativo'. Diferentemente, em AU, 'parasita' remete à entrada 'parasito', que apresenta cinco acepções, das quais há uma etiqueta, cujos sentidos marcados no dicionário escolar não são rotulados em AU.

Outra obra dicionarística inserida no conjunto daquelas pertencentes ao grupo do Tipo 2 e de que traremos aqui para analisar algumas de suas unidades lexicográficas corresponde a Saraiva Júnior (2009), a fim de traçar pontos comparativos com outros dicionários. Vejamos 'galera':

\begin{tabular}{c|c} 
Quantidade de acepções em Saraiva Júnior (2009) & Rubrica(s) \\
\hline 3 & pop, gír \\
Quadro 7: Entrada 'galera' \\
Fonte: Elaborado pelo autor
\end{tabular}

No Saraiva Júnior (2009), a marcação é explicitada em itálico após a numeração das acepções; por exemplo, em 'galera', temos três acepções, das quais duas apresentam rubricas pop ("grupo de torcedores, torcida”) e gír ("pessoal, turma, grupo de amigos”), assim como em Geiger (2011), ambas apresentam uma linguagem acessível a seu público-alvo. Em HO, das sete acepções, seis são rotuladas, duas coincidem com aquelas de Saraiva Júnior (2009), porém, aqui, com 'Rubrica: futebol. Regionalismo: Brasil. Uso: informal' e 'Derivação: por extensão de sentido. Regionalismo: Brasil. Uso: informal'. Já em AU, em 'galera²', encontramos os dois sentidos apontados em Saraiva Júnior (2009), porém, essa remete a outras entradas que abarcam esses sentidos "1. V. torcida ${ }^{1}$ (2). 2. V. turma $(7)^{\prime}$.

Analisemos 'galho': 
Quadro 8: Entrada 'galho'

Fonte: Elaborado pelo autor

Em 'galho', temos duas acepções, sendo que a segunda apresenta rubrica gír (com o sentido de briga), exemplificada por duas expressões: a) 'dar galho' (“trazer um problema”); b) 'quebrar um galho' (“ajudar a resolver uma situação difícil”). Em HO, há oito acepções para 'galho', das quais cinco possuem rubricas, além de duas locuções, ambas marcadas ('Regionalismo: Brasil. Uso: informal.'): 'botar o galho dentro' e 'quebrar (um) galho' (esta última coincidente com uma das encontradas no Saraiva Júnior). Por outro lado, em AU, há sete acepções (com quatro rubricas) e sete locuções (com cinco rubricas), dentre as quais há a coincidência tanto aos sentidos apontados por esse dicionário escolar quanto a outras etiquetas variadas, tais como, 'Bras. Gír., 'Bras. MG', 'Bras. AL Chulo', 'Bras. Chulo', 'Chulo' para a entrada 'galho'.

Passemos a analisar 'pintar':

\begin{tabular}{c|c} 
Quantidade de acepções em Saraiva Júnior (2009) & Rubrica(s) \\
\hline 5 & gir \\
\hline Quadro 9: Entrada 'pintar' &
\end{tabular}

Fonte: Elaborado pelo autor

Do ponto de vista geográfico, é difícil atestar que uma lexia corresponde a uma gíria, a não ser que seja realizada uma ampla investigação; apesar de que seja possível afirmar que, predominantemente, gírias fazem parte da linguagem urbana, verificamos que a etiqueta gír é frequentemente usada pelos dicionários escolares e, por exemplo, em 'pintar', há cinco acepções, sendo uma delas gír ("aparecer"), porém, até que ponto seria uma marca de uso nacionalmente entendida como tal?

No HO, essa mesma entrada possui vinte acepções, que contemplam aquelas de Saraiva Júnior (2009), nas quais duas apresentam rubricas ('Regionalismo: Brasil. Uso: informal.'), além da locução ' pintar e bordar' (rubrica informal). No AU, há trinta e duas acepções (sete rubricas 'Bras.', 'Bras. Gír., 'Bras. RS'), as quais também abarcam as cinco desse dicionário escolar, além de três locuções (uma delas com a rubrica 'Bras. Fam.'). Notemos que, para essa entrada, foram etiquetadas três diferentes marcas (gíria, informal e familiar), claramente levando a uma má compreensão ou a um não entendimento de uso para seus consulentes infantis.

Na sequência, temos 'pinto':

\begin{tabular}{c|c} 
Quantidade de acepções em Saraiva Júnior (2009) & Rubrica(s) \\
\hline 2 & pop \\
Quadro 10: Entrada 'pinto’ & \\
Fonte: Elaborado pelo autor &
\end{tabular}

Também muito comumente ao se referir a um nível ou a um estilo da língua, encontramos a etiqueta pop para se fazer a marcação em dicionários escolares, como em 'pinto', que apresenta duas acepções, uma delas possui a rubrica pop (“o pênis”). No HO, essa entrada tem quatro acepções, três rubricas, sendo uma delas ('informal') também referente ao órgão genital masculino; além disso, há duas locuções ("como um pinto" e "ser pinto”), consistindo, em sua segunda, a etiquetagem 'Regionalismo: Brasil. Uso: informal'. Em AU, há cinco acepções e cinco locuções, dentre elas, há a rubrica 'chulo’ para se referir ao órgão em questão, reforçando um valor diferente das marcações 'informal' e 'pop', pois 'chulo' leva ao entendimento de que se trata de um sentido grosseiro, rude, baixo ou que a unidade lexicográfica é usada de modo ordinário pela camada mais baixa da sociedade. Essas diferenças de etiquetagem observadas ('informal' no HO, pop no Saraiva Júnior, 'chulo’ em AU e familiar em Geiger) por si só já levantariam muitas discussões e poderiam suscitar um novo artigo, porém, não vamos nos aprofundar, neste momento, nesse direcionamento. 
Passemos à 'pipa':

\begin{tabular}{c|c} 
Quantidade de acepções em Saraiva Júnior (2009) & Rubrica(s) \\
\hline 3 & pop \\
$\begin{array}{c}\text { Quadro 11: Entrada 'pipa' } \\
\text { Fonte: Elaborado pelo autor }\end{array}$ &
\end{tabular}

Ainda outro exemplo de etiquetagem por pop é 'pipa', que contém três acepções, sendo uma delas pop ("pessoa gorda e baixa”), no Saraiva Júnior, assim constatando que há lexicógrafos e dicionaristas que têm preferência por utilizar o rótulo 'popular' (ou 'pop’) a fim de caracterizar um vocábulo de uso próprio do povo, em geral. No HO, em 'pipa', há cinco acepções, três delas estão etiquetadas, sendo que aquela coincidente com Saraiva Júnior - Regionalismo: Brasil. Uso: informal, jocoso - é "pessoa gorda e de baixa estatura". Também 'pipal', em AU, indica cinco acepções, em que três são rotuladas, sendo "pessoa baixa e gorda" com a etiqueta 'pop'.

Por fim, temos 'traçar':

\begin{tabular}{c|c} 
Quantidade de acepções em Saraiva Júnior (2009) & Rubrica(s) \\
\hline 5 & fam \\
Quadro 12: Entrada 'traçar' \\
Fonte: Elaborado pelo autor
\end{tabular}

A falta de um esclarecimento sobre o valor das rubricas torna ainda mais difícil determinar qual seria a diferença, por exemplo, entre 'familiar' e 'popular'. Em 'traçar', há cinco acepções, uma delas está etiquetada com fam ("comer ou beber com grande prazer”). No $\mathrm{HO}$, 'traçar' apresenta quatro entradas, porém, em nenhuma delas se encontra a coincidência de sentido com esse dicionário escolar. Já em AU, 'traçar' apresenta duas entradas, em 'traçar", também expressa a marca 'Bras. Fam.' ("beber ou comer com grande apetite ou avidez; devorar, bater"), coincidindo com Saraiva Júnior.

Com isso, pretendemos trazer para a ordem do dia reflexões acerca das escolhas lexicográficas de etiquetagem em algumas das lexias presentes nas obras estudadas, pois, seguindo de perto essas unidades lexicográficas, notamos claramente a presença ideológica a qual os lexicógrafos pretendem seguir com suas definições a seu público-alvo - a criança. Pelas explanações definitórias encontradas nos dicionários escolares infantis desta pesquisa, evidenciam-se generalizações (por meio do uso frequente das etiquetas 'gíria' ou 'popular') ou omissões (por exemplo, pela não ocorrência de 'chulo') que nos levam a refletir se essas convicções, propositadamente, precisam ser mantidas, conservadas, perduradas no âmbito escolar aos consulentes infantis.

\section{7 À GUISA DE CONCLUSÃO}

Ao se analisar dois dicionários escolares infantis - Geiger (2011) e Saraiva Júnior (2009) -, comparando-os a duas obras dicionarísticas legitimadas pela sociedade brasileira (HO e AU), evidenciou-se a necessidade, para a constituição de um verbete, de etiquetagem das unidades lexicográficas. Como foi visto nos exemplos trazidos neste artigo, há discrepância na conceituação e apresentação das marcas de uso nos dicionários. À vista disso, mesmo não sendo o propósito deste artigo, acreditamos que seja providencial ao trabalho lexicográfico a elaboração de uma lista que possa vir a contemplar a padronização dessas/nessas obras, assim, teríamos uma reorganização junto aos rótulos já existentes a fim de colaborar para a busca do consulente.

É preciso que haja um relacionamento harmônico, além de critérios categóricos para a compilação de uma nomenclatura voltada a um público-alvo específico, para que se evite a ocorrência de equívocos linguísticos por parte do consulente ao fazer uso das obras 
lexicográficas, portanto, uma consonância entre os dicionários se faz necessária. Além disso, a questão da regularidade deveria ser pensada para a formulação microestrutural, visto que, conforme os exemplos analisados, não se evidencia um rigor científico que se pressupõe vital à feitura dessas obras.

Logo, dessas análises, deduzimos que os dicionários supracitados pretendem, por meio de suas definições e marcas de uso, buscar uma suposta neutralidade, pelo uso de uma linguagem simples e concisa, mas que carrega a ideologia de seus lexicógrafos. Outro aspecto diz respeito à recolha da nomenclatura dessas obras, dado que não é explicitada sua feitura, por vezes evidenciada como inapropriada. Com efeito, sobre a etiquetagem, principalmente para os dicionários escolares infantis, seria preciso que fosse muito mais utilizada e detalhada em suas nuanças de sentido para o benefício da compreensão dos consulentes, assim, incluindo julgamentos que possam expressar uma avaliação, apreciação ou mesmo interpretação sobre determinada realidade as quais atribuímos às unidades lexicográficas quando em contexto de uso.

\section{REFERÊNCIAS}

BÉJOINT, H. Modern lexicography: An Introduction. Oxford: Oxford University Press, 2000.

BIDERMAN, M. T. C. A estrutura mental do léxico. In: QUEIROZ, T. A. Estudos de Filologia Linguística. São Paulo, EDUSP, 1981. p. 131-145.

BIDERMAN, M. T. Glossário. Alfa, São Paulo, v. 28 (supl.), p. 135-144, 1984.

BIDERMAN, M. T. Léxico e Vocabulário Fundamental. Alfa, São Paulo, v. 40, p. 27- 46, 1996.

BORBA, F. S. Organização de dicionários: uma introdução à Lexicografia. São Paulo, UNESP, 2003.

BORBA, F. S. Léxico e herança social. In: MARCHEZAN, R. C.; CORTINA, A. (org.). Os fatos da linguagem, esse conjunto heteróclito. Araraquara: Cultura Acadêmica Editora, 2006. p. 81-96.

BRASIL. Ministério da Educação. Secretaria de Educação Básica. Com direito à palavra: dicionários em sala de aula (PNLD 2012: Dicionário). Brasília: Ministério da Educação, Secretaria de Educação Básica, 2012.

GEIGER, P. (org.). Caldas Aulete - Dicionário escolar da língua portuguesa. 3. ed. São Paulo: Globo, 2011.

FAJARDO, A. Las marcas lexicográficas: concepto y aplicación práctica en la Lexicografía española. Revista de Lexicografía, v. 111, p. 31-57, 1997.

GARRIGA ESCRIBANO, C. Marcas. In: GUERRA, A. M. M. (coord.). Lexicografía española. España: Editorial Ariel, 2003.

GUTIÉRREZ CUADRADO, J. Ideología e lexicografía. In: VICENTE, F. S.; GARRIGA, C.; LOMBARDINI, H. E. Ideolex. Estudios de Lexicografia e Ideología, 2011.

FERREIRA, A. B. H. Novo Dicionário Eletrônico Aurélio versão 7.0. 5. ed. Curitiba: Editora Positivo Informática LTDA, 2010.

HAENSCH, G. et al. La Lexicografia: de la Linguística teórica a la Lexicografia práctica. Madrid: Gredos, 1982.

HOUAISS, A. Dicionário Eletrônico Houaiss da Língua Portuguesa versão 1.0. Editora Objetiva, 2009.

Forum lingüístic., Florianópolis, v.17,n.3,p.5004-5017, jul./set. 2020 
KRIEGER, M. G. Políticas públicas e dicionários para escola: o Programa Nacional do Livro Didático e seu impacto sobre a Lexicografia Didática. Cadernos de Tradução, Florianópolis, v. 2, n. 18, p. 235-252, 2006.

LARA, L. F. El contenido proposicional del acto: la definición lexicográfica. In: LARA, L. F. Teoría del diccionario monolingüe. México: El Colegio de Mexico, 1996. p. 167-231.

LARA, L. F. O dicionário e suas disciplinas. In: ISQUERDO, A. N.; KRIEGER, M. G. (org.). As ciências do léxico: lexicologia, lexicografia, terminologia. Campo Grande: Editora UFMS, 2004. p. 133-152.

ORLANDI, E. P. Discoursive lexicography. Alfa, São Paulo, v. 44, p. 97-114, 2000.

PORTO DAPENA, J. Á. Manual de técnica lexicográfica. Madrid: Gredos, 2002.

STREHLER, R. G. As marcas de uso nos dicionários. In: OLIVEIRA, A. M. P.; ISQUERDO, A. N. (org.). As ciências do léxico: Lexicologia, Lexicografia, Terminologia. Campo Grande: Editora UFMS, 1998. p. 171-180.

SARAIVA JÚNIOR. Dicionário da Lingua Portuguesa Ilustrado. 3. ed. São Paulo: Saraiva. 2009.

VILELA, M. Estruturas léxicas do português. Coimbra: Almedina, 1979.

WELKER, H. A. Marcas de uso. In: WELKER, H. A. Dicionários: uma pequena introdução à lexicografia. Brasília: Thesaurus. 2004.

WELKER, H. Panorama Geral da Lexicografia Pedagógica. Brasília: Editora Thesaurus, 2008.

ZAVAGLIA, C. Sistematização crítica em Lexicografia e Lexicologia. 92f. Tese (Livre-docência em Lexicologia e Lexicografia) Instituto de Biociências, Letras e Ciências Exatas, Universidade Estadual Paulista, São José do Rio Preto, 2009.

\section{()(1) $\circledast$}

Recebido em 30/12/2019. Aceito em 05/04/2020. 